\title{
Effects of inclusion of cetirizine hydrochloride in $\beta$-cyclodextrin
}

\author{
Magdalena Paczkowska ${ }^{1} \cdot$ Mikołaj Mizera $^{1} \cdot$ Kornelia Lewandowska ${ }^{2} \cdot$ Maciej Kozak $^{3} \cdot$ Andrzej Miklaszewski $^{4}$. \\ Judyta Cielecka-Piontek ${ }^{1}$
}

Received: 17 September 2017 / Accepted: 27 April 2018 / Published online: 4 May 2018

(c) The Author(s) 2018

\begin{abstract}
Following the preparation of inclusion complex of cetirizine (CTZ) and $\beta$-cyclodextrin ( $\beta$-CD), the compound was investigated to assess the possibility of modifying the physicochemical properties (solubility, release, stability, permeability) of CTZ after complexation that are vital for subsequent formulation studies involving the said complex. Changes in FT-IR/ Raman spectra, DSC thermograms and XRD diffractograms confirmed the formation of a CTZ- $\beta$-CD system. Hydrophilic interaction chromatography with a DAD detector was employed to determine alterations of the CTZ concentration during studies following complexation. An analysis of a phase-solubility diagram of $\mathrm{c}_{\mathrm{CTZ}}=f \mathrm{c}_{\beta \text {-CD }}$ indicated a linear rise in the solubility of CTZ as the concentration of $\beta$-CD increased. The inclusion of CTZ in a system with $\beta$-CD significantly reduced the instability of CTZ in the presence of oxidizing factors. It was also found that regardless of the $\mathrm{pH}$ of the acceptor fluids used in the release studies an increase was observed in the concentration of CTZ in CD system compared to its free form. The ability to permeate artificial biological membranes manifested by CTZ after complexation was enhanced as well. In summary, CD has significant potential to mask the bitter taste of CTZ and to counter the instability induced by oxidizing factors.
\end{abstract}

Keywords Cetirizine hydrochloride $\cdot \beta$-Cyclodextrin $\cdot$ Quantum chemical calculations $\cdot$ Chemical stability $\cdot$ Solubility $\cdot$ Permeability

\section{Introduction}

Cetirizine hydrochloride (CTZ) is a second-generation $\mathrm{H}_{1}$-receptor antagonist antihistamine drug [1]. It is used to treat the symptoms of allergies, chronic urticaria, hay fever, angioedema, hives and as a treatment adjunct in asthma [2]. CTZ belongs to the second generation of antihistamines that are less able to cross the blood-brain barrier and therefore do not cause side effects such as sedation, drowsiness, and

Judyta Cielecka-Piontek

jpiontek@ump.edu.pl

1 Department of Pharmaceutical Chemistry, Faculty of Pharmacy, Poznan University of Medical Sciences, Grunwaldzka 6, 60-780 Poznan, Poland

2 Department of Molecular Crystals, Institute of Molecular Physics, Polish Academy of Sciences, Smoluchowskiego 17, 60-179 Poznan, Poland

3 Department of Macromolecular Physics, Adam Mickiewicz University, Umultowska 85, 61-614 Poznan, Poland

4 Institute of Materials Science and Engineering, Poznan University of Technology, Jana Pawła II 24, 60-965 Poznan, Poland decreased cognitive processing [3-6]. Cetirizine is a racemic mixture of two enantiomers: levocetirizine and dextrocetirizine. Although levocetirizine shows 30 -fold greater efficiency against the $\mathrm{H}_{1}$-receptor, the majority of preparations contain a racemic mixture of two enantiomers because no correlation has been found between the content of the optical isomers and the perception of a bitter taste. Efforts to find ways of masking the bitterness of cetirizine have been dictated by two important issues: the possibility of using the drug in pediatric patients depending on its therapeutic safety and effectiveness in the context of a growing tendency for allergic reactions in that subpopulation, and the need to select taste-masking substances able to reduce the susceptibility of CTZ to degradation under the influence of oxidizing factors. One of the impurities listed in Pharmacopoeial guidelines is 1,4-bis-[(4-chlorophenyl)phenylmethyl] piperazine, formed as a result of the action of an oxidizing factor. The formation of related impurities as a consequence of CTZ oxidation or subsequent degradation of a specified Pharmacopoeial impurity has also been reported [7-9].

Considering that it is necessary to mask the taste of $\mathrm{CTZ}$ and to ensure its stability, cyclodextrins (CDs) may be 
recommended as auxiliary substances with the potential to satisfy those requirements. They are cyclic oligomers composed of six, seven or eight glucose monomers, linked by $\alpha-1,4$-glucose bonds, referred to as $\alpha$-, $\beta$ - or $\gamma$-cyclodextrins, respectively. It has been reported in some studies that CDs can form inclusion (host-guest) complexes with several pharmaceutical substances containing hydrophobic molecules [10-12]. When used as complexing agents, CDs can also help to increase drug solubility and to enhance drug permeability through the membrane barrier thus improving the bioavailability of the guest molecule [13-19]. Moreover, there have been reports of employing CDs as carrier systems for targeted drug delivery [20-23].

With regard to masking the unpleasant taste of CTZ, successful attempts reported in the literature involved complexation with $\beta$-CDs [24-26]. Several patent descriptions refer to pharmaceutical formulations of CTZ containing CDs as agents for the reduction of its bitter taste [27, 28]. Fanara et al. presented the formation of solutions of CTZ and $C D$ that diminished the unpalatable flavor as a result of the pre-formation of a drug-cyclodextrin complex. Friesen et al. incorporated CTZ into multiparticulates (55 wt \% glyceryl mono-, di- and tri-behenates, COMPRITOL 888, and $10 \mathrm{wt} \%$ poloxamer, PLURONIC F-127) to provide a dissolution-retarded form of the drug and then chewable tablets containing a dissolution-retarded form of the CTZ and $\beta$-cyclodextrin complex. It should be emphasized that all of the reports on the preparation of the CTZ- $\beta$-CD complex referred to co-precipitation as a preparation method. The solvents were water $[25,26,29,30]$, a mixture of water and methanol [31], and DMSO [24]. The preparation methods presented in the literature necessitate, due to the prospect of using the complex in solid drug forms, the removal of solvents and monitoring their volatile residues. Considering the predicted possibility of incorporating CTZ into the structure of $\mathrm{CD}$, three domains have been specified: the phenyl and chlorophenyl groups as well as the piperazinyl ethoxy acetic moiety (Fig. 1a). The first two are hydrophobic and may contribute to inclusion complexation. The third is hydrophilic and as such it is favored by the exterior hydrophilic group of $\mathrm{CD}$. The structure of a cyclodextrin complex was determined by Stojanov et al. during studies using NMR spectroscopy [25]. They confirmed the stereochemistry of CTZ complexes with $\alpha-, \beta$ - and $\gamma-\mathrm{CD}$, and indicated two possible CD binding sites in the CTZ structure: the phenyl and chlorophenyl rings. However, so far no reports have described the effect of complexing CTZ and $\beta$-CD on the properties (solubility, stability, release, permeability) important for future formulation work on such complexes. Therefore, the aim of the present work was to prepare and characterize a cetirizine inclusion complex with $\beta$-cyclodextrin regarding changes in the solubility, stability, release and permeability of cetirizine resulting from the formation of the said complex. The methods used for identification studies of the CTZ- $\beta-C D$ complex included Fourier transform infrared (FT-IR) and Raman spectroscopies, X-ray powder diffraction (XRPD) as well as differential scanning calorimetry (DSC). Changes in the concentration of CTZ during the evaluation of its solubility, stability, release and permeability were determined with a HILIC method [7].

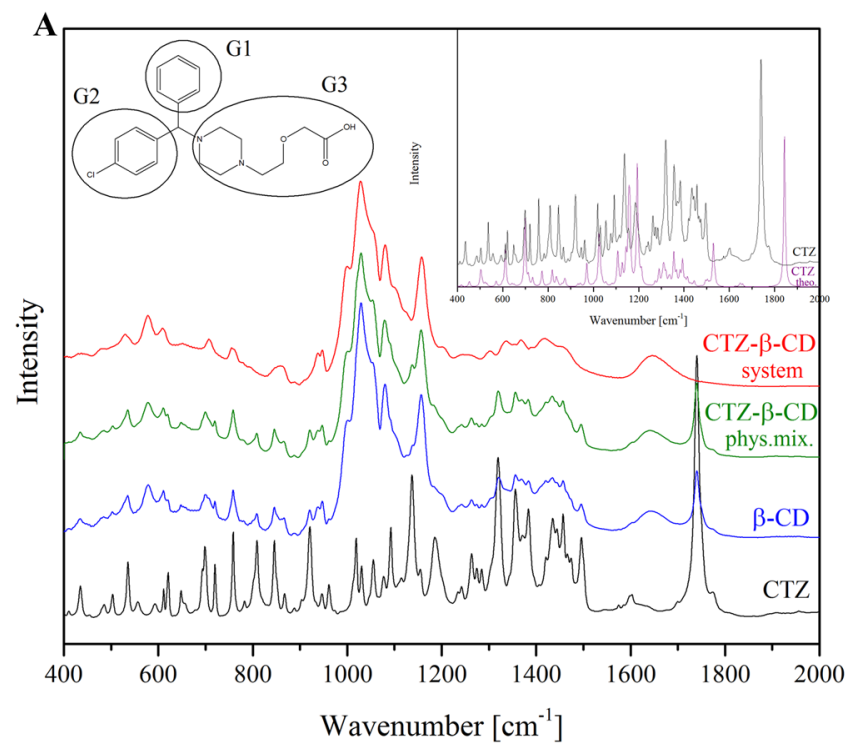

Fig. 1 FT-IR (a) and Raman spectra (b) of CTZ, $\beta$-CD, CTZ- $\beta$-CD physical mixture and CTZ- $\beta-C D$ system, and calculated IR CTZ spectra (B3LYP/6-31G) (CTZ theo.) with chemical structure of ceti-

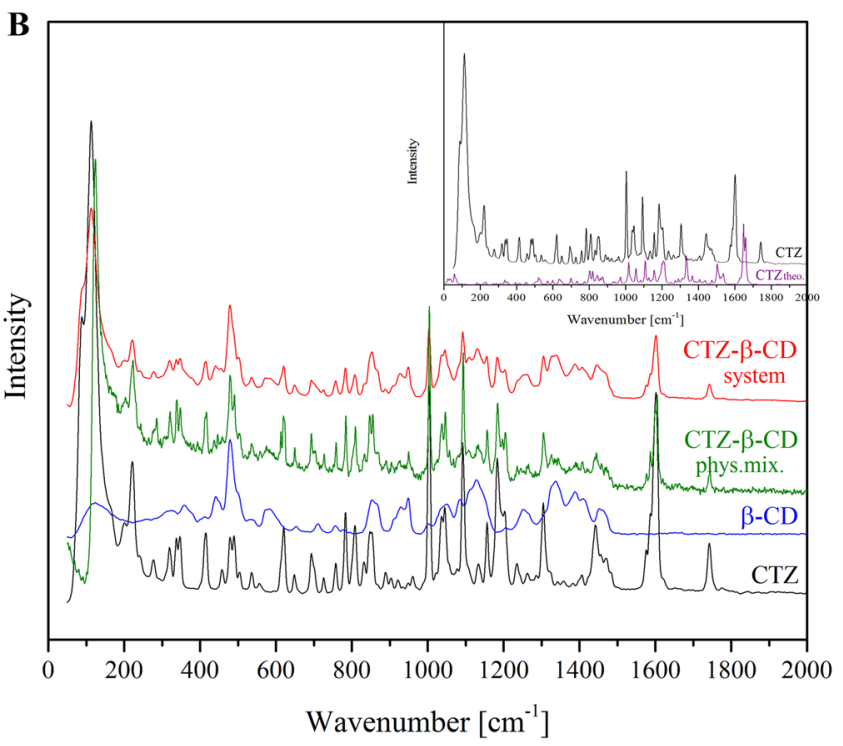

rizine showing main groups ( $G 1$ phenyl group, G2 chlorophenyl group, $G 3$ piperazinyl ethoxy acetic acid) 


\section{Materials and methods}

\section{Materials}

Cetirizine hydrochloride (purity $>98 \%$ ) in bulk substance was supplied by India PVT LTD (Navi Mumbai, India), while $\beta$-cyclodextrin (purity $>98 \%$ ) by Sigma-Aldrich (Poznan, Poland). Hydrochloric acid, sodium hydroxide solvent, hydrogen peroxide, potassium dihydrogen phosphate, potassium bromide and all other chemicals were obtained from Avantor Performance Materials (Gliwice, Poland). Acetonitrile of an LC grade was supplied by Merck KGaA (Darmstadt, Germany) and formic acid (100\%) by Avantor Performance Materials (Gliwice, Poland). High-quality pure water was prepared using an Elix SA 67120 Millipore purification system (Warsaw, Poland).

\section{Preparation of the CTZ- $\beta-C D$ system}

CTZ was kneaded with a mixture of $\beta-\mathrm{CD}$ and water at a molar ratio of 1:1. After drying at $313 \mathrm{~K}$, the substances were ground to powder. The CTZ- $\beta$-CD system was kept in an atmosphere of controlled humidity.

\section{Characterization of the CTZ- $\beta-C D$ system}

During identification studies of the CTZ- $\beta$-CD system, spectroscopic (FT-IR, Raman, XRPD) and thermal (DSC) techniques were used. A HILIC method was applied for the measurement of CTZ concentration changes during studies of solubility, chemical stability, release and permeability through biological membranes.

\section{Fourier transform infrared spectroscopy (FT-IR)}

Infrared spectra for $\mathrm{CTZ}, \beta-\mathrm{CD}$, the $\mathrm{CTZ}-\beta-\mathrm{CD}$ physical mixture and the CTZ- $\beta$-CD system were recorded with a Fourier transform infrared FT-IR Bruker Equinox $55 \mathrm{spec}-$ trometer equipped with a Bruker Hyperion 1000 microscope. All samples were measured in an absorption mode, in a frequency range of $400-2000 \mathrm{~cm}^{-1}$ and at a resolution of $4 \mathrm{~cm}^{-1}$. To analyze changes in positions and intensity in the experimental spectra of the CTZ- $\beta$-CD system, quantum chemical calculations based on DFT with B3LYP functional and 6-31G $(\mathrm{d}, \mathrm{p})$ basis set were conducted to obtain theoretical spectra of CTZ. The analysis of changes in experimental spectra and determination of binding domains of API in system was conducted according to theoretical spectrum of CTZ. All calculations were performed by using the Gaussian
09 package [32]. The scale factor applied to theoretical spectra was 0.964.

\section{Raman spectroscopy}

Raman scattering spectra for CTZ, $\beta$-CD, CTZ- $\beta-C D$ physical mixture and the CTZ- $\beta$-CD system were obtained with a LabRAM HR800 spectrometer (HORIBA Jobin Yvon) with the laser $(\mathrm{He}-\mathrm{Ne})$ excitation $\lambda_{\mathrm{exc}}=633 \mathrm{~nm}$. All of the spectra were an average of 500 scans with a resolution of $4 \mathrm{~cm}^{-1}$. In each case the power of the laser beam at the sample was less than $1 \mathrm{~mW}$ to avoid damage to the sample.

\section{X-ray powder diffraction (XRPD)}

For base sample analysis and the confirmation of system formation, an X-ray powder diffraction (XRPD) technique was used. The obtained patterns were collected by a PANalitycal Empyrean system with a Cu lamp (1.54056 ̊). The measurements were carried out in the scanning range between $3^{\circ}$ and $50^{\circ}$ at $2 \theta$ range using a step size of $0.017^{\circ}$ and a step time of $15 \mathrm{~s} / \mathrm{step}$ with source parameters of $45 \mathrm{kV}$ and $40 \mathrm{~mA}$.

\section{Differential scanning calorimetry (DSC)}

DSC analyses of CTZ, $\beta$-CD, CTZ- $\beta$-CD physical mixture and the CTZ- $\beta-C D$ system were performed by using a DSC 204 Phoenix differential scanning calorimeter (Netzsch, Germany). The samples of $2 \mathrm{mg}$ were enclosed in aluminum cells, and heated at a scanning rate of $5 \mathrm{~K} \mathrm{~min}^{-1}$ from 273 to $523 \mathrm{~K}$ in a helium atmosphere with a flow rate of $40 \mathrm{~mL} \mathrm{~min}{ }^{-1}$. The obtained DSC data were analyzed (determination of enthalpy, phase transition temperatures, etc.) using the computer program TA (Netzsch).

\section{HILIC method}

The Ultimate 3000 LC system (Dionex Thermoline Fisher Scientific, Germany) included a photodiode array detector was used which was equipped with a high-pressure pump (UltiMate 3000), an autosampler (UltiMate 3000) and a DAD detector (UltiMate 3000). Data were collected and processed by Chromeleon software version 7.0 from Dionex Thermoline Fisher Scientific (US). Chromatographic separation was performed on a Poroshell 120 Hilic $(4.6 \times 150 \mathrm{~mm}$, $2.7 \mu \mathrm{m})$ column using a mobile phase composed of acetonitrile- $0.1 \%$ formic acid $(20: 80 \mathrm{~V} / \mathrm{V})$ at a flow rate of $1.0 \mathrm{~mL} \mathrm{~min}^{-1}$. The injection volume was $5.0 \mu \mathrm{L}$. The wavelength of detection was controlled at $235 \mathrm{~nm}$. The HILIC method was validated in regards to CTZ determination, including selectivity of determination in the presence of degradation products forming during oxidation [7]. 


\section{Studies of the CTZ- $\beta-C D$ system}

\section{Phase solubility studies of CTZ- $\beta-C D$ system}

The phase-solubility profile of the CTZ- $\beta$-CD system was determined according to the method of Higuchi and Connors [33]. Excess amounts of CTZ were added to samples of $\beta$-CD $\left(0.5-10.0 \mathrm{mmol} \mathrm{L}^{-1}\right)$, followed by water, and kneaded for $1 \mathrm{~h}$ at $298 \mathrm{~K}$, within which time the equilibrium of the CTZ system was achieved. Samples containing a physical mixture of CTZ- $\beta$-CD were ground for $1 \mathrm{~h}$ at $298 \mathrm{~K}$. The concentrations of CTZ in each sample were determined by an HILIC method. Phase-solubility studies were performed in triplicate; from which the apparent 1:1 stability constant was calculated. The phase-solubility profile of CTZ was obtained by plotting the solubility of CTZ as a function of $\beta$-CD concentration. The following equation was applied to establish the apparent stability constant for CTZ $-\beta-\mathrm{CD}$ :

$K_{1: 1}=\frac{\text { Slope }}{\mathrm{S}_{0}(1-\text { slope })}$

where $S_{0}$ is the intercept and slope is the angular coefficient of the fitted straight line.

\section{Stability studies of the CTZ- $\beta-C D$ system}

Due to the degradation of CTZ in the presence of an affecting factor $\left(\mathrm{H}_{2} \mathrm{O}_{2}\right)$, the impact of the oxidizing factor concentration on CTZ in free form and after complexation was investigated. Samples of CTZ- $\beta-C D$ for stability studies were prepared by dissolving an accurately weighed $39.2 \mathrm{mg}$ (containing $10.0 \mathrm{mg}$ of free $\mathrm{CTZ}$ ) in $20.0 \mathrm{~mL}$ of an equilibrated solution to $353 \mathrm{~K}$ in glass-stoppered flasks, where samples were exposed to oxidizing factor in different concentrations. At specified times, samples of the reaction solutions $(1.0 \mathrm{~mL})$ were collected, instantly cooled, and chromatographic determination was conducted. The concentration changes of CTZ and CTZ- $\beta$-CD were studied in aqueous solutions in hydrogen peroxide, with the concentration of $\mathrm{H}_{2} \mathrm{O}_{2}$ ranging from 2 to 5\% [7]. To verify $\mathrm{k}_{\text {obs }}$ determined for the degradation of CTZ in free and complexed forms, a parallelism test was used. The following equations were applied to establish the significant differences of stability plots of CTZ in free and complexed forms:

$t_{0}=\frac{a_{1}-a_{2}}{S_{a_{1}-a_{2}}}$ where $\sum_{i=1}^{n_{1}}\left(y_{i 1}-\bar{y}_{i 1}\right)^{2}$ and $\sum_{i=1}^{n_{2}}\left(y_{i 2}+\bar{y}_{i 2}\right)^{2}$ are the sum of the squares of the difference in the deviation of the regression curve determined experimentally.

\section{In vitro release study of the CTZ- $\beta-C D$ system}

The release of CTZ from the CTZ- $\beta$-CD system was studied with the help of an Agilent 708-DS dissolution apparatus. A standard paddle method was used at $310 \pm 0.5 \mathrm{~K}$ with a stirring speed of $50 \mathrm{rpm}$. CTZ in free form, a physical mixture of CTZ- $\beta-C D$ and the CTZ- $\beta-C D$ system weighed into gelatin capsules were placed in spring to prevent flotation of the capsule on the surface of the liquid. The so-obtained samples were placed in $500 \mathrm{~mL}$ media of simulated gastric fluids ( $\mathrm{pH} 1.2$ ) and phosphate buffer ( $\mathrm{pH} 5.0,6.2$ and 7.4) simulating the gastro-intestinal environment. Release samples $(5.0 \mathrm{~mL})$ were collected at specified time intervals with the replacement of an equal volume of temperature-equilibrated media and filtered through a $0.45 \mu \mathrm{m}$ membrane filter. The concentrations of CTZ in acceptor solutions were determined by using a HILIC method [7]. The reported value s are arithmetic means of six measurements.

The model proposed by Moore and Flanner to compare the release profiles is based on two-factor values, $f_{1}$ and $f_{2}$ $[34,35]$. The difference factor $\left(f_{1}\right)$ measures the percent error between two curves over all time points and $f_{2}$ is a logarithmic transformation of the sum-squared error of differences between the test $T_{j}$ and reference $R_{j}$ system over all time points according to the formulas below:

$f_{1}=\frac{\sum_{j=1}^{n}\left|R_{j}-T_{j}\right|}{\sum_{j=1}^{n} R_{j}} \times 100$

$f_{2}=50 \times \log \left(\left(1+\left(\frac{1}{n}\right) \sum_{j=1}^{n}\left|R_{j}-T_{j}\right|^{2}\right)^{-\frac{1}{2}} \times 100\right)$

where $n$ is the sampling number, $R_{j}$ and $T_{j}$ are the percents dissolved of the reference (CTZ) and test products (CTZ- $\beta$-CD system) at each time point $j$. Dissolution profiles are similar when the $f_{1}$ value is close to 0 and $f_{2}$ is close to 100 (FDA guidelines suggest that two profiles are similar if $f_{2}$ is between 50 and 100).

$S_{a_{1}-a_{2}}=\sqrt{\frac{\sum_{i=1}^{n_{1}}\left(y_{i 1}-\bar{y}_{i 1}\right)^{2}+\sum_{i=1}^{n_{2}}\left(y_{i 2}+\bar{y}_{i 2}\right)^{2}}{n_{1}+n_{2}-4} \times\left(\frac{1}{\sum_{i=1}^{n_{1}}\left(x_{i 1}-\bar{x}_{1}\right)^{2}}+\frac{1}{\sum_{i=1}^{n_{2}}\left(x_{i 2}-\bar{x}_{2}\right)^{2}}\right)}$ 


\section{Permeability studies}

Differences in the gastrointestinal permeability of CTZ in free and complexed forms were investigated by using a PAMPA method (parallel artificial membrane permeability assay). The system consisted of a 96-well microfilter plate and a 96-well filter plate and was divided into two chambers: a donor at the bottom and an acceptor at the top, separated by a $120-\mu m$-thick microfilter disc coated with a $20 \%(\mathrm{w} / \mathrm{v})$ dodecane solution of a lecithin mixture (Pion, Inc.). Solutions of CTZ and the CTZ- $\beta$-CD system $\left(0.30 \mathrm{mmol} \mathrm{L}^{-1}\right)$ in water were prepared in a different 96-well filter plate and added to the donor compartments. The donor solution was adjusted to $\mathrm{pH} 5.0,6.2$ or 7.4 (NaOH-treated universal buffer). The plates were put together and incubated at $310 \mathrm{~K}$ for $4 \mathrm{~h}$ in a humiditysaturated atmosphere. The concentrations of CTZ in free
Table 1 Selected characteristic vibronic features of CTZ

\begin{tabular}{|c|c|c|c|}
\hline $\begin{array}{l}\text { Theory scaled } \\
\left(\mathrm{cm}^{-1}\right)\end{array}$ & $\operatorname{IR}\left(\mathrm{cm}^{-1}\right)$ & $\operatorname{Raman}\left(\mathrm{cm}^{-1}\right)$ & Approximate description \\
\hline 589 & 612 & & $\mathrm{C}-\mathrm{O}-\mathrm{H} b+\mathrm{C}-\mathrm{O}-\mathrm{C} b$ \\
\hline 617 & 648 & 649 & $\mathrm{C}-\mathrm{C}-\mathrm{C} \boldsymbol{b}$ in $\mathrm{G} 1$ and $\mathrm{G} 2$ \\
\hline 672 & 697 & 694 & $\mathrm{O}-\mathrm{H} w+b r \mathrm{G} 2$ ring \\
\hline 687 & & 726 & $\mathrm{C}-\mathrm{H} w$ in $\mathrm{G} 1$ and $\mathrm{G} 2+b r \mathrm{G} 1$ and $\mathrm{G} 2$ \\
\hline 745 & 758 & 757 & $\mathrm{C}-\mathrm{H} w$ in $\mathrm{G} 1$ and $\mathrm{G} 2+b r \mathrm{G} 1$ and $\mathrm{G} 2$ \\
\hline 773 & 783 & 784 & $b r \mathrm{G} 3+\mathrm{C}-\mathrm{H} r$ at $\mathrm{G} 3+\mathrm{C}-\mathrm{H} w$ at $\mathrm{G} 1$ and $\mathrm{G} 2$ \\
\hline 789 & 808 & 808 & $b r \mathbf{G 1}$ and $\mathrm{G} 2+\mathrm{C}-\mathrm{H} w$ in $\mathrm{G} 1$ \\
\hline 813 & 846 & 848 & $\mathrm{C}-\mathrm{C} s$ at $\mathbf{G 3}+\mathrm{C}-\mathrm{O} s$ at $\mathbf{G 3}+\mathrm{C}-\mathrm{N} s$ \\
\hline 829 & & 851 & $\mathrm{C}-\mathrm{H} w$ in $\mathrm{G} 1$ \\
\hline 844 & 867 & & $\mathrm{C}-\mathrm{H} r$ \\
\hline 936 & 961 & 961 & C-O $s$ at G3 \\
\hline 979 & & 1004 & $\mathrm{C}-\mathrm{C}-\mathrm{C} b$ in $\mathrm{G} 1$ and $\mathrm{G} 3$ \\
\hline 988 & 1018 & & $\mathrm{C}-\mathrm{C} s$ in $\mathrm{G} 1$ and $\mathrm{G} 2+\mathrm{C}-\mathrm{N} s$ \\
\hline 1019 & & 1045 & $b r \mathrm{G} 1+\mathrm{C}-\mathrm{C} s$ at $\mathrm{G} 3$ \\
\hline 1069 & 1093 & 1093 & $\mathrm{C}-\mathrm{H} r$ in $\mathrm{G} 1$ and $\mathrm{G} 2+\mathrm{C}-\mathrm{Cl} s$ \\
\hline 1102 & 1137 & & $\mathrm{C}-\mathrm{N} s+\mathrm{C}-\mathrm{H} w+\mathrm{C}-\mathrm{O} s$ \\
\hline 1114 & & 1157 & $\mathrm{C}-\mathrm{N} s+\mathrm{C}-\mathrm{C} s$ at $\mathbf{G 3}+\mathrm{C}-\mathrm{H} r$ \\
\hline 1151 & 1185 & 1183 & $\mathrm{C}-\mathrm{O}-\mathrm{H} b+\mathrm{C}-\mathrm{O} s$ at $\mathbf{G 3}$ \\
\hline 1168 & & 1204 & $\mathrm{C}-\mathrm{H} r$ \\
\hline 1227 & & 1235 & $\mathrm{C}-\mathrm{H} w$ \\
\hline 1243 & 1242 & & $\mathrm{C}-\mathrm{H} w$ \\
\hline 1266 & 1263 & & $\mathbf{C}-\mathbf{H} t$ \\
\hline 1285 & & 1304 & $\mathbf{C}-\mathbf{H} t$ \\
\hline 1306 & 1320 & & $\mathrm{C}-\mathrm{H} w$ at $\mathbf{G 3}$ \\
\hline 1344 & 1384 & & $\mathrm{C}-\mathrm{O}-\mathrm{H} b$ at $\mathrm{G3}+\mathrm{C}-\mathrm{C} s$ at $\mathrm{G3}+\mathrm{C}-\mathrm{H} w$ at $\mathbf{G 3}$ \\
\hline 1420 & & 1407 & $\mathrm{C}-\mathrm{H} s c$ at $\mathrm{G} 3$ \\
\hline 1449 & & 1443 & $\mathrm{C}-\mathrm{H} s c$ at $\mathrm{G} 3$ \\
\hline 1474 & 1495 & & $\mathbf{C}-\mathbf{H} s c$ \\
\hline 1599 & 1605 & 1603 & $\mathrm{C}-\mathrm{C} s$ in $\mathrm{G} 1$ and $\mathrm{G} 2$ \\
\hline 1777 & 1739 & 1743 & $\mathrm{C}=\mathrm{O} s$ \\
\hline 2799 & & & $\mathrm{C}-\mathrm{H} s$ between $\mathrm{G} 1$ and $\mathrm{G} 2$ \\
\hline 2843 & & & $\mathrm{C}-\mathrm{H} s$ at $\mathrm{G} 3$ \\
\hline 2906 & 2869 & & $\mathrm{C}-\mathrm{H} s$ at $\mathrm{G} 3$ \\
\hline 2986 & 2951 & & $\mathrm{C}-\mathrm{H} s$ sym. and asym. \\
\hline 3087 & 3054 & & $\mathrm{C}-\mathrm{H} s$ sym. and asym. in $\mathrm{G} 1$ and $\mathrm{G} 2$ \\
\hline 3611 & 3439 & & $\mathrm{O}-\mathrm{H} s$ \\
\hline
\end{tabular}

The most important characteristic vibrational bands of CTZ involved in the interaction with B-CD are marked as bold

$s$ Stretching, $b$ bending, $r$ rocking, $w$ wagging, $s c$ scissoring, $t$ twisting, oop out of the plane, $b r$ breathing, G1 phenyl group, $G 2$ chlorophenyl group, $G 3$ piperazinyl ethoxy acetic group 
and complexed forms were determined by using the HILIC method in the donor and acceptor compartments after $4 \mathrm{~h}$ of incubation.

The apparent permeability coefficient $\left(\mathrm{P}_{\text {app }}\right)$ was calculated by using the Eq. 6 as follows:

$P_{a p p}=\frac{-\ln \left(1-\frac{C_{A}}{C_{\text {equilibrium }}}\right)}{S \times\left(\frac{1}{V_{D}}+\frac{1}{V_{A}}\right) \times t}$

where $V_{D}$ is the donor volume, $V_{A}$ the acceptor volume, $C_{\text {equilibrium }}$ the equilibrium concentration $C_{\text {equilibrium }}=C_{D} \times V_{D}+C_{A} \times V_{A} / V_{D}+V_{A}, C_{D}$ the donor concentration, $C_{A}$ the acceptor concentration, $S$ the membrane area and $t$ is the incubation time (in seconds). Compounds with $\mathrm{P}_{\text {app }}<1 \times 10^{-6} \mathrm{~cm} \mathrm{~s}^{-1}$ are classified as ones with low permeability and those with $\mathrm{P}_{\text {app }}>1 \times 10^{-6} \mathrm{~cm} \mathrm{~s}^{-1}$ as ones with high permeability [36]. To verify that $\mathrm{P}_{\text {app }}$ determined for permeability of CTZ in free and complexed forms was statistically different, ANOVA test was used.

\section{Results and discussion}

The results presented in this paper were discussed with the focus on two areas: the procedure of identifying the CTZ- $\beta-C D$ system and the evaluation of the effect of complexation on the solubility, stability, release and permeability of CTZ through an artificial membrane simulating gastrointestinal permeation as compared to the free form of CTZ.

The system was obtained via a co-grinding technique and its formation was a spontaneous and repeatable process. Previous identification studies of the CTZ- $\beta$-CD system relied on NMR spectroscopy [25]. The present work aimed to confirm the formation of the system by using spectroscopic (FTIR/Raman, XRPD) and thermal (DSC) methods, thus adopting a novel approach to the identification of the CTZ- $\beta-C D$ system.

The types of bands, their location and intensity were determined for a CTZ molecule in free form and compared with theoretical spectra based on quantum-chemical calculations performed with the use of the B3LYP functional and $6-31 \mathrm{G}(\mathrm{d}, \mathrm{p})$ as a basis set. The most important characteristic vibration bands of CTZ were defined (Table 1). In the CTZ- $\beta$-CD spectra, a decrease in the intensity of bands corresponding to vibrations between $\mathrm{C}-\mathrm{C}-\mathrm{C}$ in the phenyl and chlorophenyl rings and changes in the vibrations of $\mathrm{C}-\mathrm{H}$ in those rings were observed. Interestingly, an analysis of changes in the bands of CTZ in complexed form indicated the disappearance of bands at $1185 / 1183 \mathrm{~cm}^{-1}$ in the FT-IR/ Raman spectra corresponding to the bending vibrations

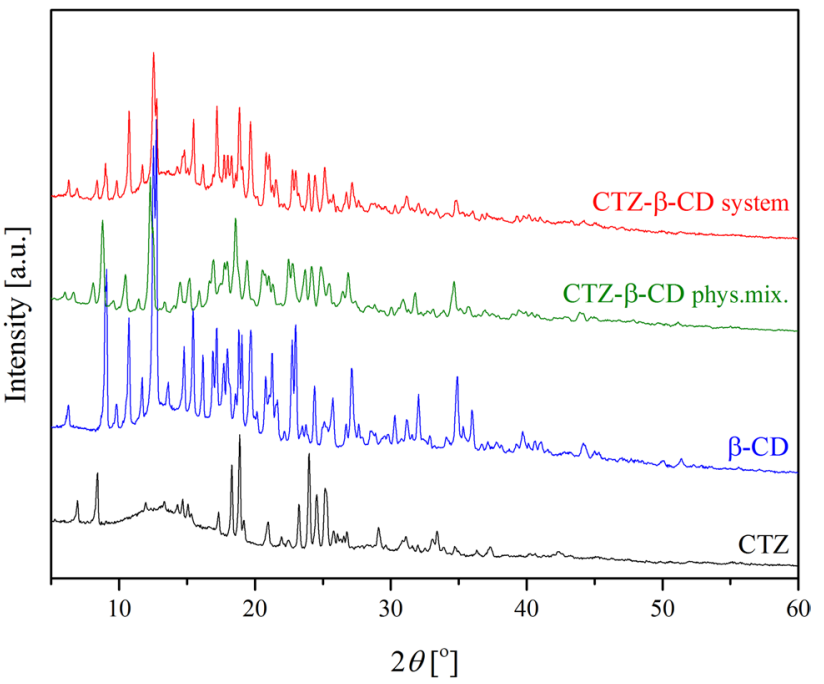

Fig. 2 XRPD powder diffraction patterns of CTZ, $\beta-C D, C T Z-\beta-C D$ physical mixture and CTZ- $\beta$-CD system

between $\mathrm{C}-\mathrm{O}-\mathrm{H}$ as well as in $\mathrm{C}-\mathrm{O}$ in piperazinyl ethoxy acetic acid, and a decrease in the intensity of a broad band at $1384 \mathrm{~cm}^{-1}$ in the FT-IR spectrum corresponding to the bending vibrations between $\mathrm{C}-\mathrm{O}$ in piperazinyl ethoxy acetic acid (Fig. 1a, b). These results confirmed the participation of two different (hydrophilic and hydrophobic) domains in a CTZ molecule in the interaction with $\beta$-CD. For physical mixture of the CTZ- $\beta-C D$ abovementioned changes were not observed.

The X-ray powder diffraction patterns for the individual components, physical mixture and the system are shown in Fig. 2. For all analyzed data the presence of crystalline form was verified. The diffraction data confirmed the formation of the system. This is interpreted in Fig. 2 as the sum relation of the spectral lines of both initial components CTZ and $\beta-C D$, the presence of which is confirmed by their peak positions. Since X-ray powder diffraction corroborated the results obtained from FT-IR and Raman spectroscopy, it may also be considered a method for the verification of incorporation (inclusion).

The DSC thermograms collected for CTZ, $\beta-\mathrm{CD}$, CTZ- $\beta$-CD physical mixture and the CTZ- $\beta-C D$ system are presented in Fig. 3. In the DSC thermogram obtained for a pure sample of CTZ, two distinct endothermic peaks are visible. The first peak was observed with a minimum at $\mathrm{T}_{1}=472.6 \mathrm{~K}$, while the second at $\mathrm{T}_{2}=482.6 \mathrm{~K}$. The thermal profile of $\beta$-CD exhibited a broad endothermic peak with a minimum at $360.0 \mathrm{~K}$, which corresponded to dehydration resulting from the presence of water molecules trapped inside the $\beta-C D$ cavity [37]. In the thermal profile of the CTZ- $\beta-C D$ system, the shape of the endothermic peak at $354.6 \mathrm{~K}$ changed and the two peaks (at $\mathrm{T}_{1}=472.6 \mathrm{~K}$ and at $\mathrm{T}_{2}=482.6 \mathrm{~K}$ ), corresponding to $\mathrm{CTZ}$, also showed changed shapes. 


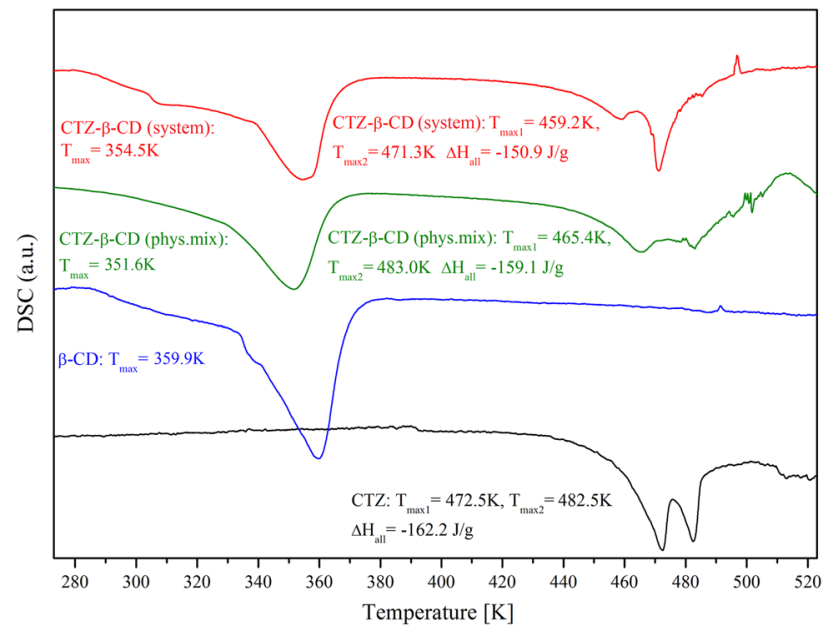

Fig. 3 DSC thermograms of CTZ, $\beta$-CD, CTZ- $\beta$-CD physical mixture and $\mathrm{CTZ}-\beta-\mathrm{CD}$ system

Previous studies reported the importance of CTZ- $\beta-C D$ system formation for obtaining a masking agent for the bitter taste of CTZ without referring to other effects of system formation. Hence, the pioneering aspect of the present work consists in investigating the physicochemical properties of CTZ after complexation.
The HILIC method was used for investigations of phasesolubility, chemical stability, release and permeability of CTZ in free and system forms. The changes of CTZ concentrations in the presence of its main product formed during oxidization were evaluated using HILIC method. The HILIC method was validated for this purpose (Table 2).

The first of the properties associated with CD is its suitability for use as a solubilizer. The phase-solubility study was conducted in the mixture $\mathrm{c}_{\mathrm{CTZ}}=f \mathrm{c}_{\beta-\mathrm{CD}}$ for a range of $\beta-C D$ concentration of $0-10 \mathrm{mmol} \mathrm{L}^{-1}$. The profile of the phase-solubility of CTZ is presented in Fig. 4. The solubility of CTZ increased linearly as a function of CD concentration, which corresponded with A-type phase-solubility profile according to Higuchi and Connors [33]. Parameters of the regression were calculated for $\mathrm{f}=\mathrm{n}-2$ degrees of freedom with $\mathrm{a}=0.05$. The calibration curve for was described by the equation $y=a x+b$. The apparent stability constant was $0.0183 \mathrm{mmol}^{-1}$. It may be suggested that a $20 \%$ increase in CTZ solubility (from 1.0 to $1.2 \mathrm{mmol} \mathrm{L}^{-1}$ ) resulted from its incorporation into $\beta-C D$ as well as from the adhesion of solubilizing CD to CTZ molecules in the area of the phenyl and chlorophenyl rings [25].

According to the BCS classification (biopharmaceutics classification system based on differences of solubility and permeability), CTZ belongs to Class III, whose members are characterized by high solubility but low permeability.

Table 2 Validation parameters of CTZ determination by HILIC method

\begin{tabular}{|c|c|c|c|c|}
\hline \multirow[t]{2}{*}{ Parameter } & \multicolumn{4}{|l|}{ Results } \\
\hline & $\mathrm{pH} 1.2$ & pH 5.0 & pH 6.2 & $\mathrm{pH} 7.4$ \\
\hline \multicolumn{5}{|l|}{ Selectivity } \\
\hline Peak symmetry factor (in range of $0.8-1.5$ required) & 1.030 & 1.066 & 1.025 & 1.027 \\
\hline Absence of interfering substances & Confirmed & Confirmed & Confirmed & Confirmed \\
\hline Limit of detection (LOD): $\mathrm{LOD}=3 \mathrm{SD} / a\left(\mathrm{mg} \mathrm{mL}^{-1}\right)$ & 0.0097 & 0.6471 & 0.6413 & 1.2500 \\
\hline Limit of quantification (LOQ): $\mathrm{LOQ}=10 \mathrm{SD} / a\left(\mathrm{mg} \mathrm{mL}^{-1}\right)$ & 0.0294 & 1.9609 & 1.9436 & 3.7879 \\
\hline \multicolumn{5}{|l|}{ Linearity: $\mathrm{y}=a \mathrm{x}+b$} \\
\hline$a \pm \mathrm{S}_{\mathrm{a}}$ & $8.24 \pm 0.11$ & $4.84 \pm 0.81$ & $6.02 \pm 0.11$ & $5.34 \pm 0.12$ \\
\hline$b \pm \mathrm{S}_{\mathrm{b}}$ & Insignificant & $6.49 \pm 0.26$ & $6.08 \pm 0.13$ & $5.04 \pm 0.12$ \\
\hline Correlation coefficient $(r)$ & 0.9998 & 0.9985 & 0.9982 & 0.9971 \\
\hline Range of linearity $\left(\mathrm{mg} \mathrm{mL}^{-1}\right)$ & $0.01-3.59$ & $0.64-5.16$ & $0.64-4.38$ & $0.57-5.72$ \\
\hline \multicolumn{5}{|l|}{ Accuracy } \\
\hline Recovery (95-105\% required) $(\%)$ & 96.07 & 95.31 & 95.39 & 95.31 \\
\hline \multicolumn{5}{|l|}{ Precision } \\
\hline Concentration $\left(\mathrm{mg} \mathrm{mL}^{-1}\right)$ & 0.5900 & 5.1600 & 4.2800 & 5.7200 \\
\hline Average of six injections $\left(\mathrm{mg} \mathrm{mL}^{-1}\right)$ & 0.5668 & 4.9182 & 4.0829 & 5.4517 \\
\hline SD & 0.0004 & 0.0070 & 0.0014 & 0.0113 \\
\hline $\operatorname{RSD}(<5 \%$ required $)$ & 0.0781 & 0.1429 & 0.0335 & 0.2177 \\
\hline
\end{tabular}

Where SD is the mean of standard deviations of determinations in the lower range of linearity and $a$ is the directional coefficient of the plotted linear function

$\mathrm{S}_{a}$ standard deviation of the slope, $\mathrm{S}_{b}$ standard deviation of the intercept, $t$ calculated values of Student's $t$ test, $\mathrm{t}_{\alpha, \mathrm{f}}=2.228$ critical values of Student's $t$ test for degrees of freedom $\mathrm{f}=10$ and significance level $\alpha=0.05$ 


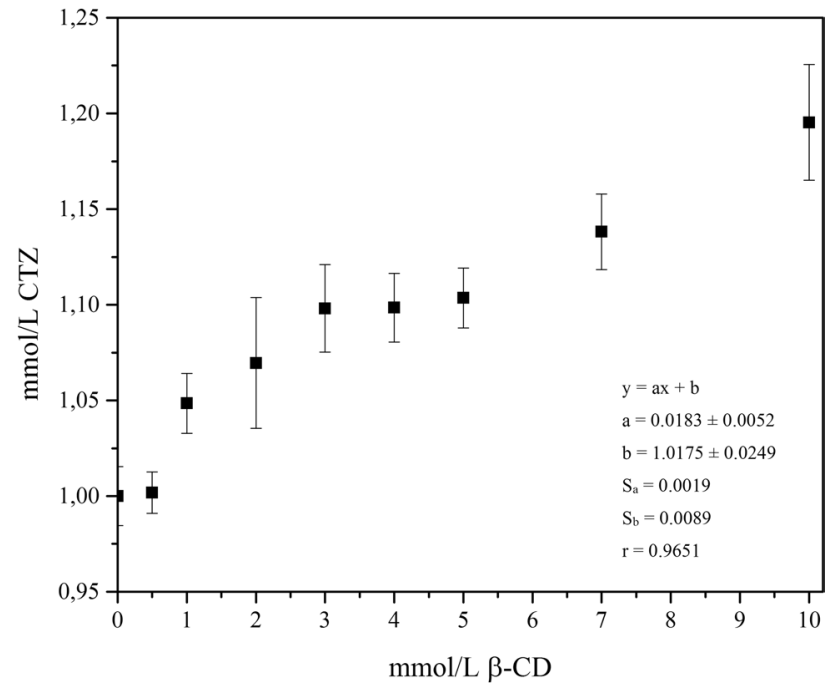

Fig. 4 Phase-solubility diagram of $\mathrm{c}_{\mathrm{CTZ}}=f \mathrm{c}_{\beta \text {-CD }}$ with statistical evaluation

Admittedly, as a result of applying cetirizine in salt form it was possible to include it in that category of drugs. It should be stressed that the solubility of CTZ is further enhanced after incorporation of its hydrophobic domains into the cavity in a CD molecule.

Another area of studies on the effects of CTZ- $\beta-C D$ system formation focused on the evaluation of $\beta$-CD impact on the chemical stability of CTZ. Previous studies showed the significant lability of CTZ in the presence of an oxidizing factor [7-9]. In order to compare the stability of CTZ in free form and after complexation with $\beta-\mathrm{CD}$, the stability studies were conducted in the presence of an oxidizing factor $\left(\mathrm{H}_{2} \mathrm{O}_{2}, \mathrm{c}=2-5 \%, \mathrm{~T}=353 \mathrm{~K}\right)$. The introduction of $\mathrm{CTZ}$ into the cavity of $\beta$-CD did not influence the mechanism of CTZ degradation (Table 3). The degradation of CTZ in free as well as in complexed form was a pseudo-first-order reaction described by the Eq. 7:

$\ln \left(C_{C T Z}\right)=\ln \left(C_{C T Z}\right)_{0}-k_{o b s}$

The semi-logarithmic plots were linear and their slopes were equal to the rate constants of the reactions with the negative sign $\left(-\mathrm{k}_{\mathrm{obs}}\right)$. To verify that $\mathrm{k}_{\mathrm{obs}}$ determined for both CTZ degradations were insignificant the parallelism test was used. $\beta$-CD had a stabilizing effect on the chemical stability of CTZ. In the HPLC chromatograms, peaks originating from an oxidized degradation product did not occur.

There have been numerous reports of the use of CD as a release modifier for selected molecules [14-16]. The release profiles for CTZ and the CTZ- $\beta-C D$ system are presented in Fig. 5. The release profiles of CTZ and the CTZ- $\beta-C D$ system were compared in simulated gastric fluids $(\mathrm{pH} 1.2)$ and phosphate buffer (pH 5.0, 6.2 and 7.4). An analysis of the release profiles showed that $\mathrm{CD}$ significantly enhanced CTZ solubility. This was observed on obtaining a physical mixture and occurred without changing the shape of the release curves. The release rate of the system was enhanced for all tested $\mathrm{pH}$ values when compared to CTZ in free form. The release process of the system started faster and quickly reached a peak concentration. For all tested values of $\mathrm{pH}$, the difference factor $f_{1}$ exceeded 15 and the $f_{2}$ factor was below 50 , which reflected major differences between the CTZ and CTZ- $\beta$-CD system release profiles and the strong influence of $\beta-C D$ on the rate of $C T Z$ release.

The last aspect of interest in the influence of CD on CTZ after complexation was changes in the permeability
Table 3 Kinetic parameters of $\mathrm{CTZ}$ degradation in free form and in complex with $\beta-\mathrm{CD}$

\begin{tabular}{|c|c|c|c|c|}
\hline Temp. (K) & $\mathrm{H}_{2} \mathrm{O}_{2}(\%)$ & $\begin{array}{l}\text { CTZ } \\
\text { Kinetic parameters }\end{array}$ & CTZ- $\beta-$ CD system & $\mathrm{t}_{0}$ \\
\hline 353 & 2 & $\begin{array}{l}\mathrm{k} \pm \Delta \mathrm{k}=(7.51 \pm 0.68) \times 10^{-7}\left(\mathrm{~s}^{-1}\right) \\
\mathrm{S}_{\mathrm{k}}=1.01 \times 10^{-4} \\
\mathrm{r}=0.9965 \\
\mathrm{n}=7\end{array}$ & $\begin{array}{l}\mathrm{k} \pm \Delta \mathrm{k}=(5.77 \pm 0.61) \times 10^{-7}\left(\mathrm{~s}^{-1}\right) \\
\mathrm{S}_{\mathrm{k}}=8.98 \times 10^{-5} \\
\mathrm{r}=0.9954 \\
\mathrm{n}=7\end{array}$ & 4.64 \\
\hline 353 & 3 & $\begin{array}{l}\mathrm{k} \pm \Delta \mathrm{k}=(1.13 \pm 0.12) \times 10^{-6}\left(\mathrm{~s}^{-1}\right) \\
\mathrm{S}_{\mathrm{k}}=2.90 \times 10^{-4} \\
\mathrm{r}=0.9876 \\
\mathrm{n}=7\end{array}$ & $\begin{array}{l}\mathrm{k} \pm \Delta \mathrm{k}=(7.32 \pm 0.11) \times 10^{-7}\left(\mathrm{~s}^{-1}\right) \\
\mathrm{S}_{\mathrm{k}}=1.57 \times 10^{-4} \\
\mathrm{r}=0.9913 \\
\mathrm{n}=7\end{array}$ & 4.39 \\
\hline 353 & 4 & $\begin{array}{l}\mathrm{k} \pm \Delta \mathrm{k}=(1.36 \pm 0.15) \times 10^{-6}\left(\mathrm{~s}^{-1}\right) \\
\mathrm{S}_{\mathrm{k}}=2.18 \times 10^{-4} \\
\mathrm{r}=0.9951 \\
\mathrm{n}=7\end{array}$ & $\begin{array}{l}\mathrm{k} \pm \Delta \mathrm{k}=(9.86 \pm 0.18) \times 10^{-7}\left(\mathrm{~s}^{-1}\right) \\
\mathrm{S}_{\mathrm{k}}=2.62 \times 10^{-4} \\
\mathrm{r}=0.9866 \\
\mathrm{n}=7\end{array}$ & 4.02 \\
\hline 353 & 5 & $\begin{array}{l}\mathrm{k} \pm \Delta \mathrm{k}=(1.75 \pm 0.24) \times 10^{-6}\left(\mathrm{~s}^{-1}\right) \\
\mathrm{S}_{\mathrm{k}}=3.56 \times 10^{-4} \\
\mathrm{r}=0.9921 \\
\mathrm{n}=7\end{array}$ & $\begin{array}{l}\mathrm{k} \pm \Delta \mathrm{k}=(1.02 \pm 0.33) \times 10^{-6}\left(\mathrm{~s}^{-1}\right) \\
\mathrm{S}_{\mathrm{k}}=4.88 \times 10^{-4} \\
\mathrm{r}=0.9582 \\
\mathrm{n}=7\end{array}$ & 4.36 \\
\hline
\end{tabular}

$t_{0}$ parameter of parallelism test 

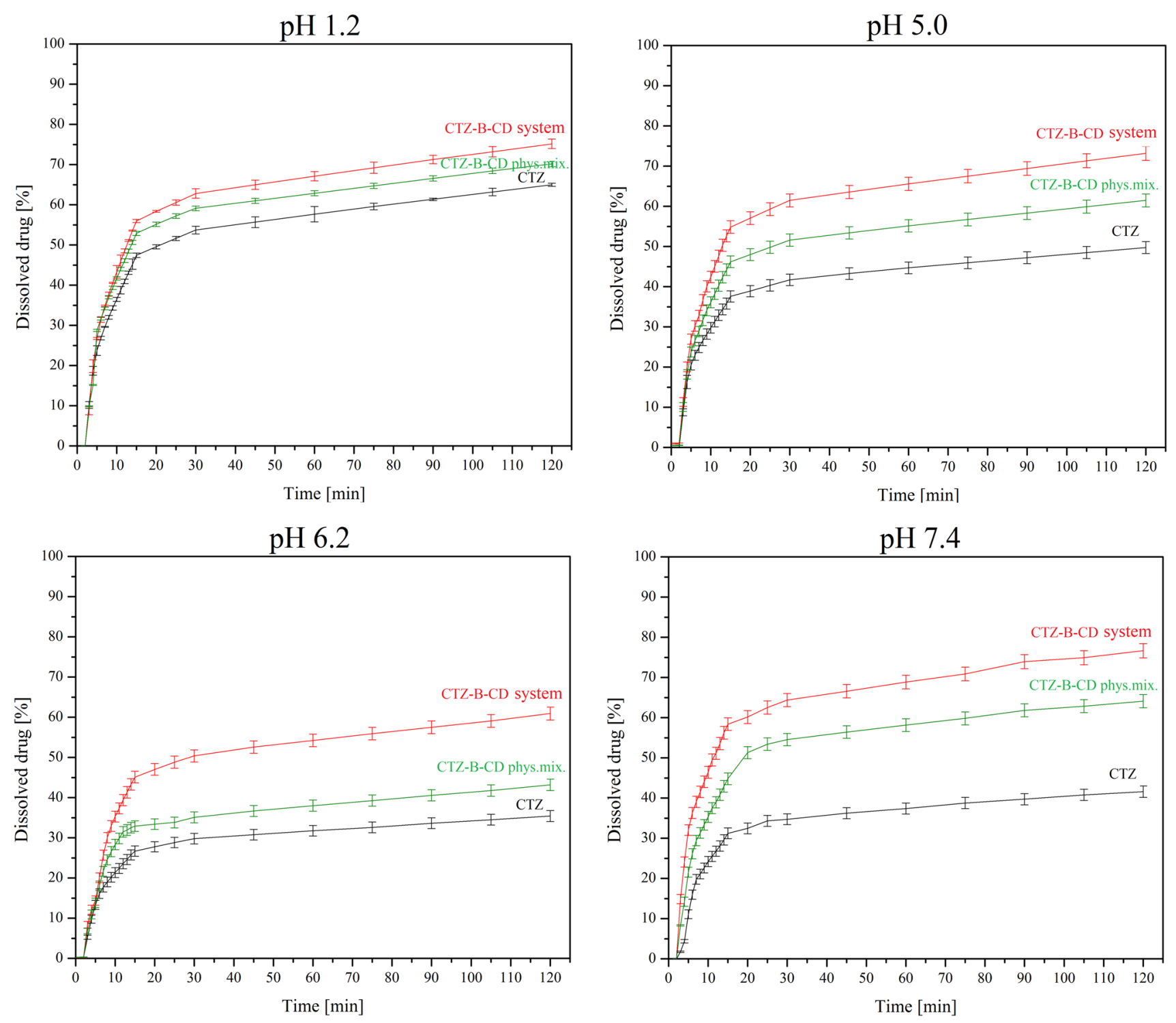

Fig. 5 Release profiles at various $\mathrm{pH}$ for $\mathrm{CTZ}, \mathrm{CTZ}-\beta-\mathrm{CD}$ physical mixture and $\mathrm{CTZ}-\beta-\mathrm{CD}$ system

of CTZ through an artificial membrane after complexation determined against a reference standard that was the permeability of CTZ in free form. The greatest permeability of CTZ was at pH $1.2\left[(1.59 \pm 0.17) \times 10^{-5} \mathrm{~cm} \mathrm{~s}^{-1}\right]$, followed by $\mathrm{pH} 5.0\left[(1.55 \pm 0.22) \times 10^{-5} \mathrm{~cm} \mathrm{~s}^{-1}\right]$ and $\mathrm{pH}$ $7.4\left[(1.33 \pm 0.17) \times 10^{-5} \mathrm{~cm} \mathrm{~s}^{-1}\right]$. The lowest permeability occurred at $\mathrm{pH} 6.2\left[(1.30 \pm 0.17) \times 10^{-5} \mathrm{~cm} \mathrm{~s}^{-1}\right]$. For the CTZ- $\beta-\mathrm{CD}$ system, the highest permeability was at $\mathrm{pH} 1.2\left[(1.69 \pm 0.13) \times 10^{-5} \mathrm{~cm} \mathrm{~s}^{-1}\right]$, followed by pH $7.4\left[(1.67 \pm 0.16) \times 10^{-5} \mathrm{~cm} \mathrm{~s}^{-1}\right]$, pH 5.0 $\left[(1.60 \pm 0.13) \times 10^{-5} \mathrm{~cm} \mathrm{~s}^{-1}\right]$ and, the lowest, at $\mathrm{pH} 6.2$ $\left[(1.50 \pm 0.16) \times 10^{-5} \mathrm{~cm} \mathrm{~s}^{-1}\right]$. The significance of differences between results obtained for those forms CTZ and CTZ- $\beta-C D$ were evaluated by using ANOVA test $\left(\mathrm{pH} 1.2-1.59 \times 10^{-5}\right.$ vs $1.69 \times 10^{-5} \mathrm{~cm} \mathrm{~s}^{-1}, \mathrm{p}=0.0001<\alpha=0.05, \mathrm{pH}$
$5.0-1.55 \times 10^{-5}$ vs $1.60 \times 10^{-5} \mathrm{~cm} \mathrm{~s}^{-1}, \mathrm{p}=0.0036<\alpha=0.05$; $\mathrm{pH} \quad 6.2-1.30 \times 10^{-5}$ vs $1.50 \times 10^{-5} \mathrm{~cm} \mathrm{~s}^{-1}$, $\mathrm{p}=0.00016<\alpha=0.05 ; \mathrm{pH} 7.4-1.33 \times 10^{-5}$ vs $\left.1.67 \times 10^{-5} \mathrm{~cm} \mathrm{~s}^{-1}, \mathrm{p}=0.00002<\alpha=0.05\right)$. The hydrophilicity of cetirizine salt pointed to diffusion as the main mechanism of permeation. Regardless of the $\mathrm{pH}$ of donor solutions, CTZ after complexation displayed greater permeability compared to its free form, which was confirmed statistically. The fact that the results of the permeability tests did not correlate with the findings of the release experiments suggested that the modification of release and the improvement of permeability were separate phenomena relative to the effect of incorporating phenyl and chlorophenyl rings into a $\beta$-CD cavity. 


\section{Conclusion}

Within the scope of the present study, the authors have demonstrated the possibility of modifying the physicochemical properties of CTZ (studied by using FT-IR, Raman, XRPD and DSC methods) as a result of its interaction with CD in the course of dry kneading. The observable effects of the process were the increased release of CTZ irrespective of $\mathrm{pH}$, the enhanced chemical stability of CTZ under oxidizing conditions and the greater permeability of CTZ through biological membranes. No correlation was found between $\mathrm{pH}$ and either CTZ release from CTZ- $\beta C D$ system or CTZ permeability. This finding should be given careful consideration in future work on the preparation of pharmaceutical formulations using so-obtained CTZ- $\beta$-CD system.

Acknowledgements This study was supported by a grant from the Ministry of Science and Higher Education (Diamentowy Grant DI2012 024342).

\section{Compliance with ethical standards}

Conflict of interest The authors declare that they have no conflict of interest.

Open Access This article is distributed under the terms of the Creative Commons Attribution 4.0 International License (http://creativeco mmons.org/licenses/by/4.0/), which permits unrestricted use, distribution, and reproduction in any medium, provided you give appropriate credit to the original author(s) and the source, provide a link to the Creative Commons license, and indicate if changes were made.

\section{References}

1. Vlastos, D., Stephanou, G.: Effects of cetirizine dihydrochloride on human lymphocytes in vitro: micronucleus induction. Evaluation of clastogenic and aneugenic potential using CREST and FISH assays. Arch. Dermatol. Res. 290, 312-318 (1998)

2. Juhlin, L., Arendt, C.: Treatment of chronic urticaria with cetirizine dihydrochloride a non-sedating antihistamine. Br. J. Dermatol. 119, 67-72 (1988)

3. Carson, S., Lee, N., Thakurta, S.: Drug class review: newer antihistamines: final report update 2. Oregon Health \& Science University, Portland (2010)

4. Golightly, L., Greos, L.: Second-generation antihistamines: actions and efficacy in the management of allergic disorders. Drugs 65, 341-384 (2005)

5. Berger, W., et al.: Impact of azelastine nasal spray on symptoms and quality of life compared with cetirizine oral tablets in patients with seasonal allergic rhinitis. Ann. Allergy Asthma Immunol. 97, 375-381 (2006)

6. Howarth, P., Stern, M., Roi, L., Reynolds, R., Bousquet, J.: Double-blind, placebo-controlled study comparing the efficacy and safety of fexofenadine hydrochloride (120 and $180 \mathrm{mg}$ once daily) and cetirizine in seasonal allergic rhinitis. J. Allergy Clin. Immunol. 104, 927-933 (1999)

7. Paczkowska, M., et al.: Hydrophilic interaction chromatography (HILIC) for the determination of cetirizine dihydrochloride.
Arabian J. Chem. (2016). https://doi.org/10.1016/j.arabj c. 2016.05 .012

8. Souri, E., Hatami, A., Ravari, N., Alvandifar, F., Tehrani, M.: Validating a stability indicating HPLC method for kinetic study of cetirizine degradation in acidic and oxidative conditions. Iran. J. Pharm. Res. 12, 287-294 (2013)

9. Dyakonov, T., Muir, A., Nasri, H., Toops, D., Fatmi, A.: Isolation and characterization of cetirizine degradation product: mechanism of cetirizine oxidation. Pharm. Res. 27, 1318-1324 (2010)

10. Loftsson, T., Brewster, M.: Pharmaceutical applications of cyclodextrins. 1. Drug solubilization and stabilization. J. Pharm. Sci. 85, 1017-1025 (1996)

11. Bhardwaj, R., Dorr, R., Blanchard, J.: Approaches to reducing toxicity of parenteral anticancer drug formulations using cyclodextrins. PDA J. Pharm. Sci. Technol. 54, 233-239 (2000)

12. Davis, M., Brewster, M.: Cyclodextrin-based pharmaceutics: past, present and future. Nat. Rev. Drug Discov. 3, 1023-1035 (2004)

13. Brewster, M., Loftsson, T.: Cyclodextrins as pharmaceutical solubilizers. Adv. Drug Deliv. Rev. 59, 645-666 (2007)

14. Muankaew, C., Jansook, P., Stefansson, E., Loftsson, T.: Effect of gamma-cyclodextrin on solubilization and complexation of irbesartan: Influence of $\mathrm{pH}$ and excipients. Int. J. Pharm. 474, 80-90 (2014)

15. Veiga, F., TeixeiraDias, J., Kedzierewicz, F., Sousa, A., Maincent, P.: Inclusion complexation of tolbutamide with beta-cyclodextrin and hydroxypropyl-beta-cyclodextrin. Int. J. Pharm. 129, 63-71 (1996)

16. Becket, G., Schep, L., Tan, M.: Improvement of the in vitro dissolution of praziquantel by complexation with alpha-, beta- and gamma-cyclodextrins. Int. J. Pharm. 179, 65-71 (1999)

17. Cappello, B., Carmignani, C., Iervolino, M., La Rotonda, M., Saettone, M.: Solubilization of tropicamide by hydroxypropyl-beta-cyclodextrin and water-soluble polymers: in vitro/in vivo studies. Int. J. Pharm. 213, 75-81 (2001)

18. Lin, H., Chean, C., Ng, Y., Chan, S., Ho, P.: 2-hydroxypropyl-beta-cyclodextrin increases aqueous solubility and photostability of all-trans-retinoic acid. J. Clin. Pharm. Ther. 25, 265-269 (2000)

19. Liu, X., Lin, H., Thenmozhiyal, J., Chan, S., Ho, P.: Inclusion of acitretin into cyclodextrins: phase solubility, photostability, and physicochemical characterization. J. Pharm. Sci. 92, 2449-2457 (2003)

20. Wong, J., Yuen, K.: Improved oral bioavailability of artemisinin through inclusion complexation with beta- and gamma-cyclodextrins. Int. J. Pharm. 227, 177-185 (2001)

21. Liu, X., Lin, H., Chan, S., Ho, P.: Biopharmaceutics of beta-cyclodextrin derivative-based formulations of acitretin in SpragueDawley rats. J. Pharm. Sci. 93, 805-815 (2004)

22. Rasheed, A.: Cyclodextrins as drug carrier molecule: a review. Sci. Pharm. 76, 567-598 (2008)

23. Paczkowska, M., et al.: Complex of rutin with beta-cyclodextrin as potential delivery system. PLoS ONE 10 (2015). https://doi. org/10.1371/journal.pone.0120858

24. Lee, C., et al.: Preparation of bitter taste masked cetirizine dihydrochloride/beta-cyclodextrin inclusion complex by supercritical antisolvent (SAS) process. J. Supercrit. Fluids 55, 348-357 (2010)

25. Stojanov, M., Wimmer, R., Larsen, K.: Study of the inclusion complexes formed between cetirizine and alpha-, beta-, and gamma-cyclodextrin and evaluation on their taste-masking properties. J. Pharm. Sci. 100, 3177-3185 (2011)

26. Ali, M., EL-Massik, M., Abdallah, O., Abdelkader, H.: Reduction of bitterness and enhancing palatability of cetirizine oral liquid dosage forms by cyclodextrins. J. Pharm. Drug Dev. 2 (2014). https://doi.org/10.15744/2348-9782.1.302 
27. Fanara, D., Berwaer, M., Nolf, P., Vranckx, H., Deleers, M.: Pharmaceutical compositions for oral administration, comprising an active substance and a cyclodextrin. (2002)

28. Friesen, D.T., Lyon, D.K., Ketner, R.J., Chu, J.H.: Taste making formulation comprising the drug in a dissolution-retarded form and/or cyclodextrin in a dissolution-enhanced form. (2008)

29. Mishra, R., Amin, A.: Optimization and characterization of rapidly dissolving films of cetirizine hydrochloride using cyclodextrins for taste masking. Int. J. PharmTech Res. 5, 536-552 (2013)

30. Stojanov, M., Larsen, K.L.: Cetirizine release from cyclodextrin formulated compressed chewing gum. Drug Dev. Ind. Pharm. 38, 1061-1067 (2011)

31. Labib, G.G.: Novel levocetirizine $\mathrm{HCl}$ tablets with enhanced palatability: synergistic effect of combining taste modifiers and effervescence technique. Drug Des. Dev. Ther. 9, 5135-5146 (2015)

32. Gaussian 09, Revision A.02, Frisch, M.J., Trucks, G.W., Schlegel, H.B., Scuseria, G.E., Robb, M.A., Cheeseman, J.R., Scalmani, G., Barone, V., Petersson, G.A., Nakatsuji, H., Li, X., Caricato, M., Marenich, A., Bloino, J., Janesko, B.G., Gomperts, R., Mennucci, B., Hratchian, H.P., Ortiz, J.V., Izmaylov, A.F., Sonnenberg, J.L., Williams-Young, D., Ding, F., Lipparini, F., Egidi, F., Goings, J., Peng, B., Petrone, A., Henderson, T., Ranasinghe, D., Zakrzewski, V.G., Gao, J., Rega, N., Zheng, G., Liang, W., Hada, M., Ehara, M., Toyota, K., Fukuda, R., Hasegawa, J., Ishida, M., Nakajima,
T., Honda, Y., Kitao, O., Nakai, H., Vreven, T., Throssell, K., Montgomery, J.A. Jr., Peralta, J.E., Ogliaro, F., Bearpark, M., Heyd, J.J., Brothers, E., Kudin, K.N., Staroverov, V.N., Keith, T., Kobayashi, R., Normand, J., Raghavachari, K., Rendell, A., Burant, J.C., Iyengar, S.S., Tomasi, J., Cossi, M., Millam, J.M., Klene, M., Adamo, C., Cammi, R., Ochterski, J.W., Martin, R.L., Morokuma, K., Farkas, O., Foresman, J.B., Fox, D.J.: Gaussian, Inc., Wallingford CT (2016)

33. Higuchi, T., Connors, K.: Phase-solubility techniques. Adv. Anal. Chem. Instrum. 4, 117-212 (1965)

34. Moore, J., Flanner, H.: Mathematical comparison of curves with an emphasis on in vitro dissolution profiles. Pharm. Technol. 20, 64-74 (1996)

35. Shah, V., Tsong, Y., Sathe, P., Liu, J.: In vitro dissolution profile comparison - statistics and analysis of the similarity factor, $\mathrm{f}(2)$. Pharm. Res. 15, 889-896 (1998)

36. Yee, S.: In vitro permeability across $\mathrm{CaCo} 3$ cells (colonic) can predict in vivo (small intestinal) absorption in man - fact or myth. Pharm. Res. 14, 763-766 (1997)

37. Maniyazagan, M., Mohandoss, S., Sivakumar, K., Stalin, T.: $\mathrm{N}$-phenyl-1-naphthylamnine/ $\beta$-cyclodextrin inclusion complex as a new fluorescent probe for rapid and visual detection of $\mathrm{Pd}^{2+}$. Spectrochim. Acta Mol. Biomol. Spectrosc. 133, 73-79 (2014) 